\title{
Leadership Intelligence and Organizational Performance of Deposit Money Banks in Rivers State, Nigeria
}

\author{
Taiye Eletu Issa ${ }^{1}$ and Emmanuel Aziegbe Akhigbe ${ }^{2}$ \\ ${ }^{1,2}$ Department of Management, University of Port Harcourt. Port Harcourt, Nigeria \\ DOI - http://doi.org/10.37502/IJSMR.2022.5202
}

\begin{abstract}
The relationship between leadership intelligence and organizational performance of deposit money banks in Rivers State, Nigeria was investigated in this study. The study used a crosssectional survey, with a total population of 215 employees from twenty deposit money banks. A total of 140 employees were chosen from the population as a sample size. In order to obtain data from the employees, a random sampling approach was used, and questionnaires were sent to respondents. The Pearson Product Moment Correlation was used to analyse the data. According to the findings, the aspects of leadership intelligence (emotional intelligence and interpersonal intelligence) have a substantial and favourable association with organizational reputation and goal attainment. As a result, the study found that having strong leadership intelligence among deposit money bank executives will improve the organization's goal attainment and reputation. It was suggested, that deposit money bank managers attend training on a regular basis in order to improve their intelligence, since this would help boost the performance of the firm.
\end{abstract}

Keyword: leadership intelligence, organizational performance

\section{Introduction}

Based on the high liquidation of some of the enterprises in banking industry, the issue of bank performance has become a pressing requirement. Improving the performance of banking organizations in the sector has become critical in order to weather the current business instability. The unprecedented nature of the corporate world has had an impact on firm performance throughout time. As a result, businesses are always looking for strategies to weather the storm in order to improve their performance and stay competitive. In this period of fierce competition in a changing environment, high organizational performance is critical. Because of the rapid advancement of technology, most banks are confronted with the challenge of figuring out how to use both human resources and accessible technology to enhance their performance and acquire a competitive advantage over competitors. Organizational performance is the "life blood" of the company, since a non-performing company is doomed to fail in a short period of time. Organizations are goal-oriented organizations, and their success is measured by how well they achieve their specified objectives. 
According to Ezigbo (2011), organizational performance is defined as a firm's capacity to effectively use its existing resources and provide outputs that are compatible with its goals, objectives, and are relevant to its stakeholders and clients. The notion of organizational performance plays a critical role in the organization's success and long-term viability. According to Ahmed and Shafiq (2014), organizational performance refers to the firm's actual result or output as compared to its anticipated outputs, goals, and objectives. They went on to say that the performance of enterprises is linked to the success of an organization. Kaplan and Norton (1992) introduced the balance score card, which encompassed four important categories of organizational performance and has been used to measure the organization's performance throughout the years. Financial viewpoint, consumer perspective, internal company perspective, and learning perspective are the four key categories. According to Hurduzeu (2015), an organization's success is determined by how well it performs in its industry.

Organizational leaders, on the other hand, are seen as the driving force behind any organization's success. As a result, their intelligence level may be quite important in enhancing the company's fortunes. Despite the fact that organizations are social systems and social entities, the leaders make the choices and conduct the actions. As a result, these executives' capacity to make well-informed decisions on how to move the entire company toward success may be dependent on their emotional, social, and interpersonal intelligence.

The amount of intelligence demonstrated by leaders in the organization aids such leaders in gaining followers' support and as a result, improves goal congruence between leaders and members of the organization. Leaders' intelligence has long been a major indicator of how effective they would be in the future (Gage \&Smith, 2016). Leaders' intelligence allows them to see things from many angles while dealing with challenges that affect the organization's performance. in organizations that operate in a multicultural environment, the higher the level of leader intelligence, the higher the performance of that organization (Nosratabadi, Bahrami, Palouzian \& Mosavi, 2020). Leaders' intelligence, according to Judge, Colbert, and Ilies (2004), improves their efficacy. In line with the above assumption, leaders' intelligence may therefore contribute to an organization's success story. Furthermore, emotional intelligence, in the form of leadership intelligence, helps the manager to appropriately manage the employees, resulting in improved worker harmony and overall organization performance. According to Pagon, Banutai, and Bizjak (2008), a leader's competency is defined as the capacity to activate and use learned information in a variety of complicated and unpredictable scenarios. Emotional intelligence, spiritual intelligence, interpersonal intelligence, and social intelligence are some of the characteristics of leadership intelligence defined by Gage and Smith (2016). It is important to recognize that in order to attain great performance, leaders require the cooperation of all essential stakeholders. As a result, the leader's intelligence is critical in obtaining complete stakeholder support and so achieving maximum performance. As a result, their emotional intelligence, social intelligence, and interpersonal intelligence are critical in influencing the workforce to improve the organization's performance. In line with the above argument, Raisiene (2014) stated that only leaders with particular intelligence are capable of addressing the organization's difficulties.

Several academic studies have been conducted throughout the years in effort to improve corporate performance. Suhag, Solangi, Larik, Lakho, and Tagar (2017) investigated the relationship between innovation and organizational performance. The study was conducted in 
Pakistan's telecommunications industry. The findings indicated that there is a strong link between organizational success and creativity. Hurduzeu (2015) investigated the influence of leadership on organizational performance. According to the findings, leadership has a considerable influence on organizational performance. Ahmed and Shafiq (2014) conducted an empirical study to investigate the link between a firm's culture and its performance. The research was conducted in Bahawalpur's telecommunications industry. The findings demonstrated that all aspects of organizational culture have a substantial impact on the organization's success. Despite the numerous academic studies on how to improve organizational performance, there is a paucity of empirical research on how leadership intelligence affects organizational performance in Nigerian deposit money banks. This study intends to bridge this gap.

\section{Statement of the Problem}

Nigeria's banking industry plays a critical part in the country's economic development. However, in recent years, the banking industry has seen a decline in performance, which has had a detrimental impact on economic activity in a variety of ways. The poor performance of deposit money institutions has led to the dissolution of most firms in the industry, resulting in the loss of job possibilities and a rise in the country's unemployment rate. Most banks have undertaken staff layoff at various periods owing to an inability to retain their personnel as a result of poor performance. This act of retrenchment has so diminished workplace morale and raised job insecurity in the banking industry, all of which may have an impact on the firm's long-term viability and performance. Furthermore, poor performance has resulted in mergers and acquisitions. Recently, the acquisitions of Skye Bank by Polaris Bank and Diamond Bank by Access Bank have demonstrated that certain banks are experiencing performance issues. However, it is considered that leadership intelligence can assist the banks in navigating difficult circumstances and positioning the organization for success. The issue of fierce competition has had a long-term impact on the success of many companies.

Despite several academic initiatives, the problem of low performance in banking organizations has remained. The association between leadership intelligence and organizational performance of deposit money banks was investigated in this work so as to tackle the problem of poor performance.

\section{Objectives of the Study}

The specific objectives are to examine the relationship between:

i. Emotional intelligence and organizational reputation.

ii. Emotional intelligence and goal attainment.

iii. Interpersonal intelligence and organizational reputation.

iv. Interpersonal intelligence and goal attainment.

\section{Research Questions}

The following research questions served as a guide in the study. What is the relationship between;

i. Emotional intelligence and organizational reputation? 
ii. Emotional intelligence and goal attainment?

iii. Interpersonal intelligence and organizational reputation?

iv. Interpersonal intelligence and goal attainment?

\section{Research Hypotheses}

The following research hypotheses are propounded as tentative answers to the research questions;

Ho1: There is no significant relationship between emotional intelligence and organizational reputation.

Ho2: There is no significant relationship between emotional intelligence and goal attainment. Ho3: There is no significant relationship between interpersonal intelligence and organizational reputation.

Ho4: There is no significant relationship between interpersonal intelligence and goal attainment.

\section{Review of Literature}

\subsection{Contingency Theory}

The most extensively used contingency model was developed by Fiedler (1967). Contingency theory is a "leader-matching" theory that tries to match the right leaders with the right situations. Contingency is so named because it says that a leader's performance is determined by how well his or her style fits the situation. Fiedler developed his thesis by studying the leadership styles of a number of different leaders in a range of settings, most notably military organizations. According to Fiedler, three key situational characteristics appear to determine whether a particular circumstance is helpful to the leader: the leader-member connection (positive or negative), mission structure (high or low), and role strength (strong or weak). The "favourables" associated with various organizational situations are defined by these three situational characteristics. Positive leader-follower connections, well-defined duties, and a clear leader role strength are the most desired scenarios. The least favourable settings, on the other side, include poor leader-follower relationships, unstructured work, and a lack of leader role control. Moderately favourable circumstances fall in between these two extremes. In this approach, there are eight different combinations of these three situational variables. Contingency theory illustrates a paradigm shift in leadership research, shifting away from an exclusive focus on the leader and toward a consideration of the situational circumstances. Its takeaway was to emphasize the need of tailoring a leader's approach to the circumstances and larger context. In everyday life, we see how some executives who excel at one organization may struggle in another with a distinct culture, values, and operating style. This theory is relevant to this inquiry because the intelligence ability of the leaders will help them know what best to do, given the situation on ground in order to enhance the performance of the firm.

\subsection{Concept of Leadership Intelligence}

The art of leadership is to persuade people to work energetically and confidently toward a common goal. The practice of encouraging individuals to direct their efforts toward the 
achievement of a given goal or set of goals is frequently defined as leadership. The art of influencing others to work freely toward the attainment of collective goals is frequently defined as leadership (Ibrahim \& Daniel, 2019). This concept may be broadened to encompass not just a willingness to labor, but also enthusiasm and certainty. The term "leadership" can be used to describe a person, a job, or a process. Mullins (2002) claims that leadership has a variety of definitions, each of which attempts to compare what each writer regards to be leadership.

Effective project management necessitates strong leadership. The art of influencing people to achieve a goal is referred to as leadership. Leaders affect behaviour by creating the vision, course, and important procedures; in other words, leadership has a huge impact on the whole project process, including other people's actions. As Muijs (2011) stated while identifying leadership as the important aspect in organizational performance, leadership may be considered as a requirement for all human undertakings. Muijs (2011) cites leadership as the fundamental aspect that separates the success of commercial and public organizations. As a consequence, it's reasonable to conclude that leadership is the process of attaining goals via the active engagement of others. The most important quality of a leader is his or her persuasive personality, which has a good impact on the work happiness and performance of those who follow them.

The ability to conceive, integrate, and master new approaches of leading people is a key component of leadership intelligence (Graziano, 2017). Affluent leaders are trustworthy, competent, motivating, inventive, and demonstrate/possess emotional intelligence soft talents, according to Leadership Intelligence. Within a collaborative setting and community, leadership intelligence is the skill of combining high-level expertise and information with personal and mutual honesty. Leaders must successfully transfer followers away from the present paradigm and across a dynamic and unstable bridge that is literally being built as it is walked through (Shippy et al, 2010). This intelligence helps businesses to function with a high level of complexity and agility in an ever-changing environment, contextualizing our leadership style through appropriate action and communication based on life values and an optimism based on business realities (Shippy et al, 2010).

\subsection{Emotional Intelligence (EI)}

Emotions have an impact on people's behaviour, decisions, and judgements. Emotionally intelligent people recognize this and instead of letting their feelings to manage them, they use their thinking to control them. EI is important for job performance, motivation, decisionmaking, and excellent management and leadership, according to academics. This intelligence includes the abilities to recognize internal emotions, stimulate emotional behaviour, describe and grasp emotional signals, and manage others' emotions. Furthermore, the phrase alludes to other people's attributes such as sensitivity, awareness, empathy, and conscientiousness (Bass, 2001).

Emotional intelligence, according to Salovey and Mayer (1990), is the ability to watch one's own and others' moods and emotions, discern between them, and utilize that information to guide one's cognition and behaviour. Emotional intelligence is a combination of non-cognitive (emotional and social) talents, competences, and skills that impact an individual's capacity to cope well with environmental demands and stresses, according to Reuven Bar-On (1996). 
Emotional intelligence, according to Maurice Elias (2001), is a set of talents that lie on the opposite side of the report card from academic abilities.

EI, according to Bar-On (2004), increases an individual's personality mix traits in an efficient manner, allowing them to fulfill the task competently (Bar-On, 2004). When a person has the capacity to measure his personality's EI level, he may be able to execute the job more competently than others since he works not only with the brain but also with the heart of the job demand. On the other hand, famous researcher and psychologist Daniel Goleman (Goleman, 1995) defines Emotional Intelligence (EI) in a broader sense. Emotional intelligence, he claims, is a type of intelligence that deals with the emotional side of life and gives a framework for comprehending other people's situations. It's the ability to recognize and regulate one's own and others' emotions, to empower oneself and repress urges, and to effectively manage interpersonal and intrapersonal interactions (Goleman, 1995). Effective results require emotional intelligence and empathy from leaders in terms of activities performed within a team in order to provide solutions to issues that need to be resolved as professionally as possible (Conţu, 2020).

\subsection{Interpersonal Intelligence}

Gardner (1983) defined interpersonal intelligence as the ability to perceive and communicate successfully with people. It necessitates effective verbal and nonverbal communication, sensitivity to emotions and temperaments, and the ability to understand a variety of viewpoints. Interpersonal intelligence is important for a leader because it allows them to understand the intentions, goals, and desires of others. This intelligence allows people to work together efficiently. Good interpersonal skills are more vital than ever for today's organizational leaders. In today's enterprises, several recent papers stress the significance of interpersonal skills in the selection of leaders. Previously command-and-control organizations have altered their priority to empowerment and devotion.

The important aspects of building a team-oriented employee are anticipated to be handled by a leader's interpersonal intelligence. There are three areas of concentration, according to Rohana and Abdullah (2017): getting top management support for teams, establishing a stimulating atmosphere for which the leader is accountable, and addressing anticipated challenges. Three steps are built from the specified emphasis area to earn executive responsibility for teams. The first step is to raise awareness among top authorities about the importance of collaborative learning. The second stage is to illustrate how the teams will carry out the task, and the third stage is to keep them updated on the team's progress at all times. Interpersonal intelligence, also known as human ability, refers to a leader's ability to work constructively with others at all levels of management, including subordinates, colleagues, and superiors; they must be able to assist others in achieving the organization's shared goal. Employee motivation, communication and active listening, persuasion, and confidence building are among these skills (Kearns et al., 2015).

\subsection{Concept of Organizational Performance}

Didier (2002) defines performance as "the achievement of the objectives established in the convergence of corporate orientations." He argues that performance is the result of a contrast 
between the outcome and the goal, rather than the finding of an outcome. This concept, according to Didier (2002), is a contrast between the result and the goal. Because both outcomes and aims change greatly among domains of activity, the author's description is confusing. Performance, according to Lebas (1995), is future-oriented, adapted to the specific qualities of each organization/individual, and based on a causal model that connects components and goods. He defines a profitable firm as one that is capable of meeting the management coalition's goals, rather than one that has already achieved them. As a result, capacity is as much an aspect of performance as it is of the future. A performance, a performance, and being a performer are all terms used by Lebas (1995). A performance is generally defined by a computed outcome that is higher than what was expected or predicted based on past research. As a result, a successful performance is frequently connected with a favourable meaning. Performance can be good or bad, and it is influenced by prior outcomes. Organizational performance, according to Cho and Dansereau (2010), refers to a company's performance in respect to its aims and objectives. Gaspary, De Moura and Wegner (2020) argue that organizational structure is a platform that shapes the organization's performance by facilitating and developing innovation and creativity at work. Furthermore, Tomal and Jones (2015) define organizational performance as the difference between an organization's actual outcomes or production and its projected outputs. The effectiveness, reliability, consistency, competitiveness, job quality, and profitability of an organizational system, according to Rolstadas (1998), is a dynamic relationship involving seven performance standards that must be met: effectiveness, reliability, consistency, competitiveness, job quality, and profitability. The achievement of the above objectives, which may be considered as performance goals, is intrinsically tied to performance. A exact definition of performance, according to Rolstadas (1998), is hard to ascertain since it is dependent on seven unspecified performance criteria. If managers and staff in the organization wish to have effective communication in the organizational flow, the leaders of the organization must have an appropriate and varied intelligence. Hence, leadership intelligence has a positive and significant effect on the performance of employees and managers (Nosratabadi et al, 2020). Leader intelligence can create the best value for the organization by combining, deploying, integrating, and interacting with the dimensions as well as managing the flow of knowledge between them (Nosratabadi et al, 2020).

\subsection{Organizational Reputation}

Fombrun (1996) defined reputation as the collective representation of a firm's previous activities and results that demonstrate the firm's ability to produce valued outcomes to a wide range of stakeholders. According to Walker (2010), Fombrun's definition highlights the reputation of perceptions, the collective perspective of all stakeholders, and comparative analysis. Walker (2010) adds two more dimensions to the equation: Reputations, whether positive or negative, are both stable and long-lasting. Deephouse and Suchman (2008) observe that reputation is fundamentally a continuous measure, with each actor being placed on a continuum from worst to best; rival, in the sense that an organization's reputation can only improve at the expense of another organization; differentiating, in the sense that reputation encourages organizations to differentiate themselves from their peers; and economic, in the 
sense that reputation encourages organizations to differentiate themselves from their competitors. Organizational reputation, according to Fombrun (2012), is a mutual assessment of a company's attractiveness to a specific community of stakeholders in relation to a reference group of enterprises with whom it competes for capital. With this word, Fombrun stresses the comparative and competitive nature of reputation (Deephouse and Suchman 2008).

Corporate reputation has been primarily conceptualized in academic literature since Fombrun (1996) as a perceptual representation or assessment of the firm by its various constituents (Winn, McDonald, \& Zietsma, 2008) and the various social expectations or corporate personality traits that people attribute to companies (Winn, McDonald, \& Zietsma, 2008). (Berens, 2004). Image and identity may be used to assess a company's reputation (Tkalac \& Vercic, 2007). Internally, identity is formed depending on the culture of the company. Existing processes, historical precedents, concepts, and acts are all part of it (Melewar, Karaosmanoglu $\&$ Paterson, 2005). The image of an organization is developed in the minds of external stakeholders; it refers to their temporal perception of the organization as impacted by direct or indirect experiences: how they understand the organization's identity at a certain moment in time (Melewar, Karaosmanoglu \& Paterson, 2005). The historical component of corporate reputation gives it a more persistent and lasting quality than the picture. Corporate reputation is defined as the collection of pictures over time, and both meanings are closely related (Mahon, 2002). It's worth emphasizing that changes in the organization's social atmosphere, as well as the organization's or rivals' strategy, can have an impact on corporate reputation (Garca de los Salmones, Herrero, \& Rodrguez del Bosque, 2005).

\subsection{Goal Attainment}

In the context of the current circumstances, the goal encompasses a basic purpose that embodies a self-contained purpose (Bond, Carlson \& Keeney, 2008). Goals are aspirational; they are statements of what an organization aims to be rather than what it is. Although this indicates that they are eternal in the sense that they will never be fully fulfilled, they may be both aspirational and time-bound in specific conundrum circumstances - they can be aspirational throughout the course of significance. To give a real-life example, enhancing the society's environment may be a goal of an organization focused on social and economic rehabilitation. A goal might be to create the finest digital brand or to diversify the market. Increased connections with local businesses, on the other hand, is unlikely to be a goal because it is currently phrased in a way that implies it is a means to an end rather than an end in and of itself, despite the fact that it does represent a means target that leads to the attainment of fundamental goals (Bond, et al 2008). The distinction between principles, goals, strategies, and finishes is made by Ackoff and Emery (1972), but this distinction is too fine for use in the operational life of a manager, where these definitions are usefully ambiguous and, in our experience, far more embedded in the common vocabulary of the individual organization. As a result, effective manifestations of what we call goals are referred to as "success factors," "objectives," and even "efficiency indicators."

The goal-setting concept states that an individual's conduct is determined by his or her ambitions and goals. Goals influence a person's attitude by organizing aggressive and attention-demanding attempts outside of regular time and motivating the participant to design 
means for reaching the goal (Locke \& Latham, 1990). According to research, more challenging goals are more likely to be achieved than illusive, simple goals. When people are focused on a goal, they have been shown to achieve better results. As a result, workers are less inclined to rely on a goal if they perceive it would be difficult to achieve (Latham, Ganegoda \& Locke, 2011).

Setting extremely difficult objectives and expectations for workers, according to goal attainment, can help workers acquire more knowledge. The impact of goal-setting philosophy is most evident in the creation of training lesson plans (Locke, Shaw, Saari \& Latham, 1981). More detailed and forceful objectives, according to Locke, Latham, and their colleagues, lead to better success improvement than more generic or uncomplicated goals. This suggests that there is a direct link between goal complexity and work performance (Locke, 2006). Goal achievement increases self-efficacy and generates a sense of pride and success, according to subsequent study (Mento, Locke \& Klein, 1992). Setting ambitious objectives raises the bar for reaching self-satisfaction and a sense of well-being, but completing goals increases one's sense of efficacy (personal effectiveness), self-satisfaction, and sense of well-being, especially when the goals are seen as tough (Wiese \& Freund, 2005).

\subsection{Empirical Review}

These authors (2006) examined the relationship between corporate reputation and financial success in Australia. The data were analysed using econometrics. Reputation and financial performance are not clearly linked (in either direction). This is in contrast to many other nations' findings. In Australia, a person's reputation is irrelevant. The current reputation measure may be inaccurate, or the finding may be due to unobserved variability in the intervening variable of managerial reputation manipulation.

According to Asree, Zain, and Razalli (2010), infrastructure-related characteristics of operational procedures, such as leadership competency and organizational culture, have an influence on workers' and customers' responsiveness (as a cumulative capability), and ultimately on performance (increase in revenue). The method used was an empirical study based on 88 hotels in Malaysia, each with a distinct rating (using structural equation modeling). The findings relate responsiveness to leadership and organizational culture. Also, responsiveness is linked to hotel sales. As a result of these results, hotels may better serve their customers due to enhanced leadership and organizational culture.

The relationship between social intelligence and leadership style was investigated by Nauman (2012). The author studied how varying degrees of virtuality influenced social intelligence and leadership style. To test assumptions, the author studied data from virtual project management practitioners in five countries. The data were analysed through regression and correlation. Task and person concern are positively correlated with social awareness and relationship management, with more virtual project team members having these attributes than not. The findings have implications for leadership and social intelligence in virtual project management. Dazel (2013) assessed 36 leaders' social intelligence and interviewed 10 CEOs to determine the impact of leader social intelligence on employee engagement (EE). Despite managers' SI capabilities, there was no correlation between manager EE ratings and follower EE ratings. Empathy appears to be the most effective SI for EE. The SI talent of Teamwork may also be 
significant. The remaining five SIs got mixed help. The evidence for direct leader SI-EE relationships was equivocal. There were strong links between EE and the SIs of Teamwork, Organizational Awareness, Empathy, and Social Awareness among the 17 leaders with the highest EE scores. Other factors affecting EE, like as job design, require more research. The study's practical consequences include investing in leader empathy and collaboration through training and coaching.

Human skills (emotional intelligence, interpersonal capability, and transformational leadership) have been studied by Sunindijo and Zou (2013) in relation to safety management and creating a good work environment in construction projects. The structural equation modeling (SEM) approach was used to analyse quantitative survey data and build relationships between research variables. According to the findings, emotional intelligence is critical in the development of interpersonal skills, transformational leadership, and safety management activities that contribute to a safe workplace. Interpersonal skills are also required to become transformative leaders who build a healthy environment, according to the study.

Albulescu (2015) examined the macroeconomic influence of financial soundness measures on bank profitability in emerging countries. Previous studies looked at the influence of banking sector and macroeconomic factors on profitability, while this one focused entirely on internal factors. Using IMF monthly data from 2005 to 2013, they conclude that non-performing loans reduce bank profitability. Liquidity has a mixed influence on bank profitability, although capitalization and interest rate margins help. Non-interest expenditures, as predicted, reduce profitability. The results are the same whether they use return on assets or return on equity to measure profitability.

Mallén et al. (2015) examined the relationship between altruistic leadership, organizational learning capacity, and performance. The sample frame contains several databases or listings of organizations that place a high value on people and are regarded good places to work $(n=251)$. Using structural equation modeling, the authors tested whether altruistic leader behaviours and organizational effectiveness are linked. Researchers found that altruistic leader behaviours and organizational performance are totally mediated by organizational learning capability. The ability to create a creative, participatory, and dialogic environment conducive to organizational learning is organizational in understanding how altruistic leader behaviours effect organizational success.

Bajali examined the relationship between emotional self-awareness, personal growth initiative, and goal attainment among final-year bachelor students (2019). They used regression correlation to examine if ESA, PGI, and GA were related. The results suggest that ESA and PGI have a positive connection with GA and a negative relationship with ESA.

Ibrahim and Daniel (2019) studied the influence of leadership on the Coca-Cola Company's organizational performance in Abuja, Nigeria. To collect primary and secondary data, 250 participants were given questionnaires. The researchers validated the questionnaire with a pretest. The hypotheses were tested using Pearson's moment product coefficient and regression. The research shows that leadership affects an organization's performance. The management style of a manager directly affects an employee's performance. The study found that participatory leadership and responsibility allocation improve employee performance and organizational goals. The study concludes that achieving organizational goals and objectives is entirely contingent on leadership style. Because leadership is critical to achieving 
organizational goals/objectives, it is advised that each corporation ensures that the correct leader is in control of their organization.

These authors examined the role of organizational identity as a mediator in the relationship between emotional intelligence and organizational success (2019). As a mediator between emotional intelligence and organizational effectiveness, organizational identity plays a role in this research. It also tries to show that employees with high emotional intelligence and a strong organizational identity deliver outstanding long-term results. The research model and associated hypotheses are analysed using a structural equation model on 314 employees. In particular, the data support the role of organizational identity as a mediator between emotional intelligence and organizational performance.

Superva, Bordás, and Lorente investigated goal orientations, emotional intelligence, and student fatigue (2020). This study included 2896 Spanish high school students aged 12 to 18 . Males $(\mathrm{N}=1614 ; 55.73 \%)$ and females $(\mathrm{N}=1282 ; 44.26 \%)$ The POSQ, TMMS-24, and Maslach Burnout Inventory Student Survey were used to collect data (MBI-SS). A correlation was found between role orientation, emotional intelligence and adaptive behaviour as well as ego orientation, academic tiredness and less adaptive conduct. Emotional intelligence, on the other hand, predicts goal-directed behaviour. Encouragement of task orientation in secondary school students may lead to adaptive behaviours that enhance academic and psychological progress.

\section{Methodology}

This study employed a cross sectional survey, which is a sort of quasi experimental design. The 20 deposit money banks in River state, Nigeria, served as the accessible population. A sample size of 140 was determined using the Krejcie and Morgan Sample Size Determination Table. As a result, 140 copies of questionnaires were given to respondents. In this investigation, a simple random sample approach was applied. This method was chosen because it provides a realistic representation of the complete population and avoids the possibility of researcher bias in the sample case selection. Emotional intelligence and interpersonal intelligence were used to assess the independent variable (leadership intelligence). 5 items were used to measure emotional intelligence (e.g., I can show a sense of humour and perspective about myself) and 7 items were used to measure interpersonal intelligence (e.g., I can show a sense of humour and perspective about myself) (e.g. The managers in my organization easily forms strong and positive relationships with others). The dependent variable (organizational performance) was measured with organizational reputation and goal attainment. Organizational reputation was measured using 7 items (e.g., My organization is a corporation whose performance you can trust) and goal attainment was measured with 6 questions (e.g. My organization achieve targeted goals before the deadline). Items were assessed on a 4-point Likert scale, with 1 indicating strong disagreement, 2 indicating disagreement, 3 indicating agreement, and 4 indicating strong agreement. Statistical Package for Social Sciences (SPSS) version 21 was used to analyse the bivariate hypotheses using the spearman rank order correlation coefficient statistical analysis.

\section{Result}


A total of 140 questionnaires were issued to respondents; $122(87 \%)$ were returned, however only 112 (80\%) were completely filled out and used in the study. The hypotheses test was conducted with a $95 \%$ confidence interval, assuming a significance level of 0.05 . The decision rule is placed at a crucial area of $p>0.05$ for null hypothesis acceptance and $p<0.05$ for null hypothesis rejection.

Table 1. Emotional Intelligence and Organizational Reputation

\section{Correlations}

\begin{tabular}{|ll|r|r|}
\hline & & \multicolumn{1}{|c|}{$\begin{array}{c}\text { Emotional } \\
\text { Intelligence }\end{array}$} & $\begin{array}{c}\text { Organizational } \\
\text { Reputation }\end{array}$ \\
\hline Emotional Intelligence & Pearson Correlation & 1 & $.566^{* *}$ \\
& Sig. (2-tailed) & & .000 \\
& $\mathrm{~N}$ & 112 & 112 \\
& Pearson Correlation & $.566^{* *}$ & 1 \\
Organizational Reputation & Sig. (2-tailed) & .000 & 112 \\
& $\mathrm{~N}$ & 112 & 112 \\
\hline
\end{tabular}

$\mathbf{H o}_{1}$ There is no significant relationship between Emotional Intelligence and Organizational Reputation.

Table 1 shows that there is a significant relationship between Emotional Intelligence and Organizational Reputation ( $\mathrm{p}=.000$ and rho $=0.566$ ), so we conclude that Emotional Intelligence is related to Organizational Reputation. We reject the null hypothesis and restate that there is a significant relationship between Emotional Intelligence and Organizational Reputation based on the decision rule of $\mathrm{p}<0.05$ for null rejection.

Table 2. Emotional Intelligence and Goal Attainment

\section{Correlations}

\begin{tabular}{|ll|r|r|}
\hline & & $\begin{array}{c}\text { Emotional } \\
\text { Intelligence }\end{array}$ & Goal Attainment \\
\hline Emotional Intelligence & Pearson Correlation & 1 & $.361^{*}$ \\
& Sig. (2-tailed) & & .006 \\
& $\mathrm{~N}$ & 112 & 112 \\
& Pearson Correlation & $.361^{*}$ & 1 \\
Goal Attainment & Sig. (2-tailed) & .006 & 112 \\
& $\mathrm{~N}$ & 112 & \\
\hline
\end{tabular}

Ho2 There is no significant relationship between Emotional Intelligence and Goal Attainment. Table 2 shows that there is a significant relationship between Emotional Intelligence and Goal Attainment ( $\mathrm{p}=.006$ and rho $=0.361$ ), so we conclude that Emotional Intelligence is related to Goal Attainment. We reject the null hypothesis and restate that there is a significant relationship 
between Emotional Intelligence and Goal Attainment based on the decision rule of $\mathrm{p}<0.05$ for null rejection.

Table 3. Interpersonal Intelligence and Organizational Reputation

\section{Correlations}

\begin{tabular}{|ll|r|r|}
\hline & Pearson Correlation & $\begin{array}{c}\text { Interpersonal } \\
\text { Intelligence }\end{array}$ & $\begin{array}{c}\text { Organizational } \\
\text { Reputation }\end{array}$ \\
\hline Interpersonal Intelligence & Sig. (2-tailed) & 1 & $.197^{*}$ \\
& $\mathrm{~N}$ & 112 & .038 \\
& Pearson Correlation & $.197^{*}$ & 112 \\
Organizational Reputation & Sig. (2-tailed) & .038 & 1 \\
& $\mathrm{~N}$ & 112 & 112 \\
\hline
\end{tabular}

Ho3 There is no significant relationship between Interpersonal Intelligence and Organizational Reputation.

Table 3 shows that there is a significant relationship between Interpersonal Intelligence and Organizational Reputation ( $\mathrm{p}=.038$ and rho $=0.197$ ), so we conclude that Interpersonal Intelligence is related to Organizational Reputation. We reject the null hypothesis and restate that there is a significant relationship between Interpersonal Intelligence and Organizational Reputation based on the decision rule of $\mathrm{p}<0.05$ for null rejection.

Table 4. Interpersonal Intelligence and Goal Attainment

\section{Correlations}

\begin{tabular}{|ll|r|r|}
\hline & & $\begin{array}{c}\text { Interpersonal } \\
\text { Intelligence }\end{array}$ & Goal Attainment \\
\hline \multirow{2}{*}{ Interpersonal Intelligence } & Pearson Correlation & 1 & $.523^{* *}$ \\
& Sig. (2-tailed) & & .000 \\
& $\mathrm{~N}$ & 112 & 112 \\
& Pearson Correlation & $.523^{* *}$ & 1 \\
Goal Attainment & Sig. (2-tailed) & .000 & 112 \\
& $\mathrm{~N}$ & 112 & 112 \\
\hline
\end{tabular}

Ho4 There is no significant relationship between Interpersonal Intelligence and Goal Attainment.

Table 4 shows that there is a significant relationship between Interpersonal Intelligence and Goal Attainment ( $\mathrm{p}=.000$ and rho $=0.523$ ), so we conclude that Interpersonal Intelligence is related to Goal Attainment. We reject the null hypothesis and restate that there is a significant relationship between Interpersonal Intelligence and Goal Attainment based on the decision rule of $\mathrm{p}<0.05$ for null rejection. 


\section{Discussion of Findings}

Based on the above findings, the study realized that;

When looking at the bivariate analysis results for hypothesis one, it's clear that the significant value of 0.000 was less than the 0.05 significance level $(\mathrm{p}=0.000<0.05)$. This shows that Emotional Intelligence and Organizational Reputation have a substantial link. Emotional Intelligence has a 0.566 association with Organizational Reputation, according to the results of the spearman correlation (rho). This indicates that Emotional Intelligence and Organizational Reputation have a favourable and substantial link. Emotional Intelligence in the company accounts for $56.6 \%$ of the overall variation in Organizational Reputation in banks. This means that Emotional Intelligence and Organizational Reputation have a somewhat favourable and substantial association. These findings support Rosete and Ciarrochi's (2005) theory that leaders and employees have a reciprocal connection in which organizational culture affects the emotional state of the leader, which in turn affects the EI. A leader with EI skills will be able to more successfully motivate employees, leading in enhanced Reputation (Yunus et al., 2011). The spearman correlation coefficient analysis of hypothesis two reveals that there is no significant association between Emotional Intelligence and Goal Attainment. This is because the significant value of $0.006(\mathrm{p}=0.006<0.05)$ is less than the 0.05 criterion of significance. As a result, the null hypothesis is ruled out. This means that Goal Attainment is impacted in some manner for every unit increase or decrease in Emotional Intelligence. This indicates that as Emotional Intelligence evolves, so does Goal Attainment. These findings are consistent with Rajah et al. (2011), who demonstrated that EI increases the perceived authority of leaders who motivate their employees to achieve the company's goals.

The examination of hypothesis three revealed that Interpersonal Intelligence and Organizational Reputation had a substantial association. This is because the significant value of 0.038 is less than the threshold of significance of $0.05(\mathrm{p}=0.038<0.05)$. Interpersonal Intelligence has a 0.197 association with Organizational Reputation, according to the results of the spearman correlation (rho). These findings support Pradhan and Pradhan's (2015) findings that Interpersonal Intelligence is linked to Organizational Reputation. Interpersonal intelligence, according to Ssekakubo et al. (2014), may improve employee performance and, as a result, the firm's reputation.

The examination of hypothesis four revealed that Interpersonal Intelligence and Goal Attainment had a substantial association. Because the significant value of 0.000 is less than the 0.05 level of significance $(\mathrm{p}=0.000<0.05)$, this is the case. These findings are consistent with those of Sun and Hui (2012), who concluded that interpersonal intelligence was linked to goal attainment. Interpersonal intelligence, according to McNair et al. (2011), may achieve a common goal through leaders persuading teams or groups of individuals to behave correctly.

\section{Conclusion and Recommendation}

It is obvious that leadership intelligence affects the performance of deposit money banks in Rivers State, Nigeria, based on the results of the tested hypothesis. Emotional intelligence in the workplace will help to improve the company's reputation. This implies that any decline or default in the organization's emotional intelligence will be damaging to the organization's optimal reputation. Goal achievement is critical in the workplace, and it contributes to the 
organization's long-term success. In this highly competitive environment, maintaining a courteous and amicable connection is essential. As a result, interpersonal intelligence in the company is critical in order to maintain cordial relationships with diverse stakeholders and, as a result, increase the business's goal attainment. Enhancing organizational reputation necessitates interpersonal intelligence. Interpersonal Intelligence has a very high significant link with organizational reputation, according to the bivariate study results. Interpersonal intelligence aids in the achievement of the organization's objectives. This means that a drop in interpersonal intelligence will have a significant impact on organizational reputation and goal achievement. Finally, having strong leadership intelligence among deposit money bank executives will help the firm achieve its objectives and improve its reputation. The following suggestions are made based on the outcome and conclusions of this study;

i. Managers of deposit money institutions should operate in a way that allows them to comprehend the sentiments of key stakeholders, as this will allow them to handle relevant issues and improve the organization's reputation.

ii. The management of deposit money banks should attend training on a regular basis in order to improve their intelligence, since this will help the business work better.

iii. The management of deposit money banks should also guarantee that workers are effectively taught in order to develop high interpersonal intelligence, since this will improve the organization's reputation.

iv. Deposit money bank management should guarantee a more formal framework for improving interpersonal relationships between the company and its stakeholders, as this will aid in improving the organization's performance.

\section{Research Limitations and Directions for Future Studies}

Despite the detailed investigation to explore how leadership intelligence relates with performance of firms, the study was limited to the banking firms and this could affect the generalization of the research findings to other sectors of the economy. Again, all the dimension of leadership intelligence and the measures of organizational performance were not covered. The study only utilized questionnaires in gathering data with utilizing interview to get more detailed information from respondents. In alignment with the limitation, future research should investigate the link between leadership intelligence and performance of firms using a different sector and future research should utilize other dimensions of leadership intelligence and measures of organizational performance that were not used in this study.

\section{References}

1) Ackoff, R.L. \& Emery, F. (1972). On purposeful systems. Tavistock: London.

2) Ahmed, M. \& Shafiq, S. (2014). The impact of organizational culture on organizational performance. A case study of Telecom sector. Global Journal of Management and Business Research, 14(3), 20 - 29.

3) Albulescu, C.T. (2015). banks' profitability and financial soundness indicators: a macrolevel investigation in emerging countries, Procedia Economics and Finance 23, $203-209$. 
4) Asree, S., Zain, M. \& Razalli, M.R. (2010). Influence of leadership competency and organizational culture on responsiveness and performance of firms, International Journal of Contemporary Hospitality Management, 22(4), 500 - 516.

5) Bajali, R.M.H. (2019). The impact of Emotional Self Awareness (ESA) and Personal Growth Initiative (PGI) on goal attainment in final year bachelor students, school of human sciences and technology, Thesis Work Submitted to Instituto de Empresa University, May 2019.

6) Bar-On, R. (2004). The bar-on emotional quotient inventory (eq-i): rationale, description and summary of psychometric properties, In G. Geher (Ed.), measuring emotional intelligence: Common ground and controversy, 115-145. New York: Nova Science.

7) Berens, G. (2004). Corporate branding: the development of corporate associations and their influence on stakeholder reaction. Doctoral dissertation, Erasmus University Rotterdam. Rotterdam, Netherlands.

8) Bond, S.D., Carlson, K.A. \& Keeney, R.L. (2008). Generating objectives: can decision makers articulate what they want. Management Science, 54: 56-70

9) Cho, J. \& Dansereau, F. (2010). Are transformational leaders fair? A multi-level study of transformational leadership, justice perceptions, and organizational citizenship behaviours, The Leadership Quarterly, 21(3), 409-421

10) Conțu, E.G. (2020). Organizational performance - theoretical and practical approaches; study on students' perceptions, Proceedings of the 14th International Conference on Business Excellence, 398-406, DOI: 10.2478/picbe-2020-0038

11) Dazel, J. (2013). Examining the effects of leader social intelligence on employee $\begin{array}{llll}\text { engagement, Theses } & \text { and }\end{array}$ https://digitalcommons.pepperdine.edu/etd/387

12) Deephouse, D.L. \& Suchman, M.C. (2008). Legitimacy in organizational institutionalism. In The SAGE handbook of organizational institutionalism, edited by Royston Greenwood, Christine Oliver, Kerstin Sahlin, and Roy Suddaby, 49-77. Thousand Oaks, CA: Sage.

13) Evans, M.G. (1970). The effects of supervisory behaviour on the path-goal relationship. Organizational Behaviour and Human Performance, 5, 277-298.

14) Fiedler, F.F. (1967). A theory of leadership effectiveness. McGraw-Hill. New York.

15) Fombrun, C.J. (1996). Reputation: realizing value from the corporate image. Boston: Harvard Business School Press.

16) Fombrun, C.J. (2012). The building blocks of corporate reputation. In The Oxford Handbook of Corporate Reputation, edited by Michael Barnett and Timothy C. Pollock, 94-113. Oxford: Oxford University Press.

17) Gage, T. \& Smith, C. (2016). Leadership intelligence: Unlocking the potential for school leadership effectiveness, South African Journal of Education, 36(4), 1-9.

18) García de los Salmones, M, Herrero, A., \& Rodríguez del Bosque, I. (2005). Influence of corporate social responsibility on loyalty and valuation of services. Journal of Business Ethics, 61 (4), 369-385.

19) Gaspary, E., De Moura, G. L., \& Wegner, D. (2020). How does the organisational structure influence a work environment for innovation? International Journal of Entrepreneurship and Innovation Management, 24(2-3), 132-153.

20) Goleman, D. (1995). Emotional intelligence: why it can matter more than IQ. London: Bloomsbury.

21) Goleman, D. (1996), Emotional Intelligence: Why it matters more than IQ, Bloomsbury Publishing Plc, New York. 
22) House, R.J. (1971). A Path-goal Theory of Leader Effectiveness. Administrative Science Quarterly, 16, 321-328.

23) Hurduzeu, R. E. (2015). The impact of leadership on organizational performance. SEAPractical Application of Science, 1(7), 289-294.

24) Ibrahim A. U. \& Daniel C. O. (2019). Impact of leadership on organizational performance. International Journal of Business, Management and Social Research, 06(02), 367-374.

25) Inglis, R. Morley, C. \& Sammut, P. (2006). Corporate reputation and organizational performance: An Australian study, Managerial Auditing Journal, 21(9), 934-947.

26) Judge, T., Colbert, A. \& Ilies, R. (2004). Intelligence and leadership: A quantitative review and test of theoretical propositions. Journal of Applied Psychology, 89(3), 542552.

27) Latham, G.P., Ganegoda, D.B. \& Locke, E.A. (2011) Goal-Setting: A State Theory, but related to traits. In T.Chamorro-Premuzic, S. von-Stumm and A. Furnham (eds) The Wiley Handbook of Individual Differences. London. Blackwell Publishing.

28) Lebas M. J. (1995). Performance Measurement and Performance Management, International Journal of Production, 41, 1-3.

29) Mallén, F., Chiva, R., Alegre, J. \& Guinot, J. (2015). Are altruistic leaders worthy? The role of organizational learning capability, International Journal of Manpower, 36(3), $271-295$ :

30) Maurice E. (2001). A View on Emotional Intelligence and the Family from http://www.edutopia.org/maurice-elias-emotional-intelligence-and-family

31) Mcnair, D.E., Duree, C.A. and Ebbers, L. (2011). If I knew then what I know now: using the leadership competencies developed by the American association of community colleges to prepare community college presidents, Community College Review, 39(1), 3-25.

32) Melewar, T. C., Karaosmanoglu, E., \& Paterson, D. (2005). Corporate identity: concept, components and contribution. Journal of General Management, 31 (1), 59-81.

33) Mento, A.J., Locke, E.A. \& Klein, H.J. (1992). Relationship of Goal Level to Valence and Instrumentality. Journal of Applied Psychology. 77, 395-405.

34) Muijs, D. (2011). Leadership and motivation, New York: Random House

35) Mullins, L. J. (2002). Management and organizational behaviour, ( $5^{\text {th }}$ Edition) Britain: Pearson Educational Ltd.

36) Nauman, S. (2012). Patterns of social intelligence and leadership style for effective virtual project management. International Journal of Information Technology Project Management, 3(1), 49-63.

37) Northhouse, P.G. (2001). Leadership: theory and practice. Sage Publications, Inc., Thousands Oaks.

38) Nosratabadi, S., Bahrami, P., Palouzian, K. \& Mosavi, A. (2020). Leader cultural intelligence and organizational performance, Cogent Business \& Management, 7(1), DOI: $10.1080 / 23311975.2020 .1809310$

39) Pagon, M., Banutai, E. \& Bizjak, V. (2008). Leadership competencies for successful change management. Slevenian presidency of the European Union.

40) Pradhan, S. \& Pradhan, R.K. (2015). An empirical investigation of relationship among transformational leadership, affective organizational commitment and contextual performance, Vision: The Journal of Business Perspective, 19(3), 227-235.

41) Raisiene, A. G. (2014). Leadership and managerial competences in a contemporary organization from the standpoint of business executives. Economics and Sociology, $7(3), 179-193$. 
42) Rajah, R., Song, Z. \& Arvey, R.D. (2011). Emotionality and leadership: taking stock of the past decade of research, The Leadership Quarterly, 22(6), 1107-1119.

43) Rohana, N.S.M. \& Abdullah, C.Z. (2017). Leadership Competencies and Organizational Performance: Review and Proposed Framework, International Journal of Academic Research in Business and Social Sciences, 7(8), 824-831.

44) Rolstadas A. (1998). Entreprise performance measurement. International Journal of Operations and Production Management, 18, 9-10.

45) Rosete, D. \& Ciarrochi, J. (2005). Emotional intelligence and its relationship to workplace performance outcomes of leadership effectiveness. Leadership and Organization Development Journal, 26(5), 388-399.

46) Ssekakubo, J., Lwanga, F. \& Ndiwalana, G. (2014). Employee motivation, job satisfaction and organizational performance in Uganda's oil sub-sector. Global Advanced Research Journal of Management and Business Studies, 3(7), 315-324

47) Suhag, A. K., Solangi, S. R., Larik, R. S. A., Lakho, M. K. \& Tagar, A. H. (2017). The relationship of innovation with organizational performance. International Journal of Research, 5(2), $292-306$.

48) Sun, R.C. \& Hui, E.K. (2012). Cognitive competence as a positive youth development construct: a conceptual review, The Scientific World Journal, 2012, 1-7.

49) Sunindijo, R Y \& Zou, P X W (2013). The roles of emotional intelligence, interpersonal skill, and transformational leadership on improving construction safety performance, Australasian Journal of Construction Economics and Building, 13(3) 97-113;

50) Supervía, P.U., Bordás, C.S. \& Lorente, V.M. (2020). Psychological analysis among goal orientation, emotional intelligence and academic burnout in middle school students, International Journal of Environmental Research and Public Health, 17(8), $1-12$.

51) Tkalac, A., \& Vercic, D. (2007). Reputation as matching identities and images: extending Davies and Chun's (2002) research on gaps between the internal and external perceptions of the corporate brand. Journal of Marketing Communications, 13 (4), 277 290.

52) Tomal, D.R. \& Jones, K.J. (2015). A comparison of core competencies of women and men leaders in the manufacturing industry, The Coastal Business Journal, 14(1), 1325.

53) Walker, K. (2010). A systematic review of the corporate reputation review literature: definition, measurement, and theory. Corporate Reputation Review, 12, 357-387.

54) Wiese, B.S. \& Freund, A.M. (2005) Goal progress makes me happy or does it? Longitudinal findings from the work domain. Journal of Occupational and Organisational Psychology. 78, 287-304.

55) Winn, M. I., Macdonald, P., \& Zietsma, C. (2008). Managing industry reputation: the dynamic tension between collective and competitive reputation management strategies. Corporate Reputation Review, 11 (1), 35-55.

56) Yunus, H., Ghazali, K. \& Hassan, N. (2011). The influence of leader's emotional intelligence: mediating effect of leader-member exchange on employees' organizational citizenship behaviours, Interdisciplinary Journal of Contemporary Research in Business, 3(3), 1125-1134.

57) Zehir, C., Üzmez, A., Köle, M. \& Öztürk, H.Y. (2019). Effect of emotional intelligence on organizational performance: mediating role of organizational identification, The European Proceedings of Social \& Behavioural Sciences, 10(15), 262-273. 